\title{
1 A Historical Perspective
}

Since the 19th century, there has been a methodological discussion in economics about how one should analyse national economies. Walras (1834) introduced a framework he called General Equilibrium Analysis. According to Walras, in a national economy "everything affects everything." The only correct way to analyse it should be to treat the national economy as an unbroken entity and to use the tools of general equilibrium analysis. Later, many other economists have strengthened the Walras orientation. As an example, one can cite the Edgeworth diagram, which enabled us to explain the Pareto optimum. However, the work of Arrow and Debreu (1954) has constituted the cornerstone of Walrasian equilibrium theory. In fact, by proving the existence of the uniqueness of the optimum of Walrasian equilibrium-plus the two theorems of welfare-Arrow and Debreu combined abstract general equilibrium structure with realistic economic data to solve numerically for the levels of supply, demand, and price that support equilibrium across a specified set of markets. This allowed Walrasian equilibrium to become an applicable theory. It is worthwhile to recall here the contribution of Nash (1950), who introduced anticipation aspects into multi-game equilibrium, thereby achieving something like a quasi-Pareto optimum.

This school of thought is the forefather of the Leontief input-output model of production, the social accounting matrix (SAM), and microeconomic-based computable general equilibrium models (CGE).

On the other hand, Marshall (1890) criticized Walras and postulated that general equilibrium analysis is impossible in practice, because it demands too much information. Marshall's claim was that it is enough to separate from the rest of national economy the part under investigation and to analyse it within the framework he called partial equilibrium analysis. As a motivation, Marshall developed the so called ceteris paribus condition, which means "all other things remaining unchanged." Most postKeynesian macroeconomic models belong to this school of thought. Criticism against large-scale macro econometric models built in the tradition of the Cowles Commission approach began in the late 1960s. These misgivings were subsequently reflected in the Lucas critique (parameters of models may take into account the reaction effect of agents with respect to expectation-rational or not), Sims's critique (time series models), and disenchantment with the model's Keynesian foundations (IS-LM models and the Philips curve) criticised by the Chicago school.

In response, classical macro econometric modelling progressed in two parallel ways: one, the improvement of the structure of traditional models, particularly in terms of specifying the supply-side and forward-looking expectations; and the other, strengthening techniques or developing alternative techniques (the so-called no economics theory-oriented models), e.g., the LSE approach aided by the advent of co-integration analysis, vector autoregressive (VAR) systems, and dynamic stochastic general equilibrium (DSGE) models. 
Walrasian general equilibrium theory made its resurgence while the Keynesian model started declining. A major stimulus to early CGE modelling was Stone and Brown (1962). As a continuation of Leontiew's work (1941) - and to a certain degree, F. Quesnay's tableau économique (18th century) - Stone pioneered the development of the SAM framework with his 1955 article Input-Output and Social Accounts (1962). The general shape of a SAM framework was next described by Pyatt and Thorbecke (1976). Then, Pyatt and Roe (1977) published a book giving a detailed description of the example of Sri Lanka. Since then, SAMs have been applied in a wide variety of (developed and developing) countries and regions, and with a wide variety of goals, in particular, as we will see latter, for impact analysis and simulations.

While in the early 1960s CGE models were perceived as precious devises for modelling poorer economies (e.g., Adelman et al. (1978), Arrow et al. (1971), de Melo (1988)), CGE modelling of developed economies stems from Leif Johansen's 1960 sectorial growth model (MSG) of Norway as an extension of the Leontief model. The model was later extended by Harberger $(1959,1962)$. Showen, Scarf, and Walley (1984, 1972, 1992) with the presentation by Scarf (1969) of an algorithm helping to solve the model. Similarly, as far as CGE models for developed countries are concerned, since the early of 1960's, a model was developed by the Cambridge Growth Project under the initiative of Richard Stone in the UK. The Australian MONASH model is the next new generation representative of this class. Both models were dynamic (traced variables through time). Other more recent contributions may draw attention, in particular those of Jorgenson, using an econometric approach, Mc Kenzie (1959, 1981, 1987), Ginsburgh and Waelbroeck (1981, 1976), Ginsburgh and Keyzer (1997), Harris and Cox (1983), Bourguignon (1983), Decaluwe and Martens (1987, 1988). Today there are many other CGE models from different countries. One of the most well-known CGE models is the GTAP (Global Trade Analysis Project) model of world trade, which involves many researchers around the world.

Depending on, among other things, targeted time-scope analysis, the macroeconomics school of thought involved, or the approach to model estimation, nowadays there are large classes of CGE models. Readers interested in the epistemological aspects of CGE models can see-e.g., Xian (1984) Jorgenson (1984, 1998a), Ginsburgh and Keyzer (1997), McKenzie (1954) or Mansur and Whalley (1984). However, for the clarity of the document, let us now concentrate on two classes of CGE models. The first class models the reactions of the economy over a given perspective of time thus suggesting comparative static and dynamic CGE models. The second focuses on the theoretical aspects of equilibrium, seeing that economic conditions of general equilibrium are not always fulfilled.

As far as the first class of models is concerned, many CGE models around the world are static; that is, they model the reactions of the economy at only one point in time. For policy analysis, a simulation analysis is carried out and outputs are often interpreted as showing the reaction of the economy, in some future period, to one or more external shocks or policy changes. From the analytical point of view, the results 
show the difference (usually reported in percent of change) between two conditional alternative future states, that is, "what would happen if the policy shock were implemented." As opposed to dynamic models, the process of adjustment to the new equilibrium is not explicitly represented in such a model. However, details of the closure rule lead modellers to distinguish between short-run and long-run equilibriums. For example, this will be the case if the hypothesis on whether capital stocks are allowed to adjust or not.

Dynamic CGE models, by contrast, explicitly trace each variable through time at regular time steps, generally at annual intervals. While this class of model removes one of the main criticisms of CGE models, that of being unrealistic, as their analysis is based on one-year observations, at the same time, they become more challenging to construct and solve-they require, for instance, that future changes are predicted for all exogenous variables, not just those affected by a possible policy change. Furthermore, dynamic elements may arise from partial adjustment processes or from stock/ flow accumulation relations-between capital stocks and investment and between foreign debt and trade deficits.

Recursive-dynamic CGE models are those that can be solved sequentially, over time. They assume that behaviour depends only on current and past states of the economy. The construction of this class of models is less complex and such models are easier to implement in empirical research than dynamic models.

Alternatively, if agents' expectations depend on the future state of the economy, it becomes necessary to solve for all periods simultaneously, leading to full multiperiod dynamic CGE models. Recent publications cover this group of models, known as dynamic stochastic general equilibrium (DSGE) as they explicitly incorporate uncertainty about the future. It is worthwhile to add that the earliest DSGE models were formulated in an attempt to provide an internally consistent framework to investigate real business cycle (RBC) theory ${ }^{47}$.

If we consider the second class of models focusing upon the general equilibrium aspects, one may consider that most CGE models rarely conform to the theoretical general equilibrium model. For instance, the presence of imperfect competition, nonclearing markets, or externalities (e.g., pollution) will lead the economy to disequilibrium conditions.

47 See DSGE: Modern Macroeconomics and Regional Economic Modeling by Dan S. Rickman, Oklahoma State University, prepared for presentation in the JRS $50^{\text {th }}$ Anniversary Symposium at the Federal Reserve Bank of New York. 